\title{
On the Notch Effect in Low Temperature Carburized Stainless Steel under Fatigue
}

\author{
G. Minak ${ }^{\mathrm{a}}$
}

DIEM Department of Mechanical Engineering, Alma Mater Studiorum - Università di Bologna, viale Risorgimento 2, 40136 Bologna,

\begin{abstract}
The present paper describes the fatigue behaviour of carburized notched AISI 316 austenitic stainless steel specimens. Rotary four point bending fatigue tests have been performed using carburized smooth specimens with two different values of surface rugosity and notched specimen with two different stress concentration factors $\mathrm{Kt}$, of 3.55 and 6.50 and the effects of carburizing on fatigue strength and notch sensitivity were discussed. Results show a general improvement of the fatigue life due to the treatment for all the series with an apparent notch sensitivity lower than one in the case of blunt notches due to secondary effects that were singled out.
\end{abstract}

\section{Introduction}

Austenitic stainless steels are widely used in the nuclear, chemical, food and pharmaceutical industries and in biomedical applications mainly because of their excellent corrosion resistance. Many attempts have been made in recent years to engineer the surface of these stainless steels in order to improve their hardness and tribological properties without deteriorating their corrosion resistance and they had as a secondary effect the modification of the fatigue properties of those materials. Among the others [1], a possibility to improve these properties is given by different processes developed in the 80 's of the past century that consist in a Low Temperature Carburizing (LTC), that involves diffusion of large quantities of Carbon atoms into the material at a diffusion temperature below $450{ }^{\circ} \mathrm{C}$ to prevent the formation of undesired chromium carbides and the degradation of the corrosion resistance. This process produces very high surface residual stresses (1500-2000 MPa) that can slowdown both the crack nucleation and propagation phases [1-3].

In particular in [2] the effect of the residual stresses on the fatigue life was considered in a general way without limiting to the case under study.

It was concluded that the models nowadays available do not allow foreseeing the fatigue life in presence of such high residual stress fields. In addition there is no conclusive evidence that the residual stress field has more influence on the nucleation phase or more on the fracture propagation phase.

\footnotetext{
e-mail : giangiacomo.minak@unibo.it
}

This is an Open Access article distributed under the terms of the Creative Commons Attribution-Noncommercial License 3.0, which permits unrestricted use, distribution, and reproduction in any noncommercial medium, provided the original work is properly cited. 
Probably this two phases are both interested, but what is surely known is that compressive residual stresses tend to move the crack nucleation zone far from the surface towards the inner part of the specimen and more precisely to the border of the treated zone.

In [3], by means of two numerical models, the effect of the carburized surface both on the induced residual stresses and on the Vickers micro-hardness test is studied.

As a result of this study it was possible to evaluate the distribution and entity of the residual stresses basing on simple micro hardness tests.

In [1] Ceschini and Minak find a great improvement in the fatigue life of smooth specimens as a result of the LTC process.

In order to use this improved fatigue behaviour for design purposes the effect of the presence of notches must be evaluated from point of view of the quality of the process and of the fatigue performances [4,5] and in this paper the aspects of notch sensitivity and the effect of the surface roughness are experimentally investigated.

\section{Materials and Methods}

During the experimental activity a total number of 94 specimens made of AISI 316 stainless steel were tested under rotating bending fatigue at $50 \mathrm{~Hz}$, according to the ISO 1143 [6] and ISO 12107 [7] standards.

In particular 50 smooth specimens (i.e. with a theoretical stress concentration factor near to one and the geometry shown in figure 1) were tested in two conditions of surface rugosity, resulting from simple lathe turning or subsequent polishing, while in the remaining 44 specimens were machined $60^{\circ} \mathrm{V}$ notches with two different values of fillet radius: $0.4 \mathrm{~mm}$ or $0.03 \mathrm{~mm}$ (the latter was manufactured by means of a tool of radius nominally null and the resulting notch measured by means of a profilometer) as shown in figure 2 .

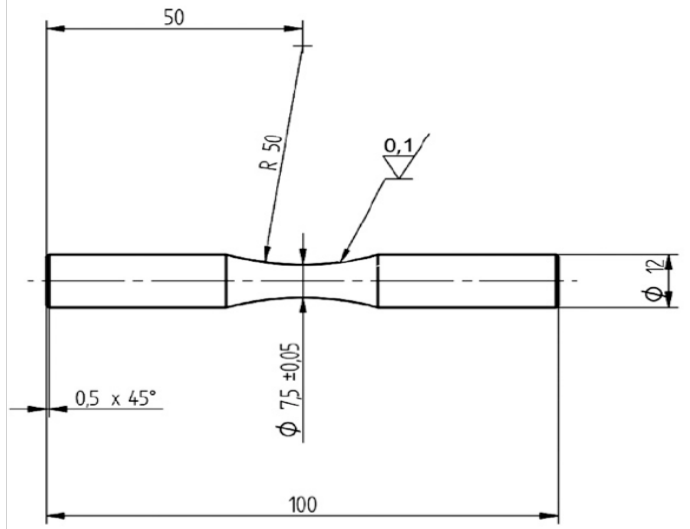

Fig. 1: Unnotched specimens geometry

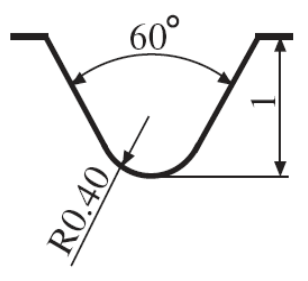

Fig. 2: Notches geometry

The theoretical stress concentration factors in these two cases were $\mathrm{Kt}=3.55$ and $\mathrm{Kt}=6.50$ respectively, as calculated by [5].

One half of these specimens were tested after solubilisation, while the remaining half part has been surface treated by LTC after machining (as said they were lathe machined or polished depending on the desired surface roughness).

Some of the broken specimens were analyzed by a Scanning Electronic Microscope in order to determine the onset point of the fracture and the thickness of the treated layer. 


\section{Results}

In the following paragraph the results of rotating bending fatigue tests of the different specimens series are reported. They were grouped in different graphs in order to highlight the most important differences in the fatigue behaviour and draw significant conclusions.

Figure 3 shows the effect of surface rugosity on the fatigue limit. It can be noticed that polishing leads, in not treated specimens, to an increment of performances of the same order of magnitude to the one due to LTC. This is due to the well-known effect provoked by the reduction of the number of possible crack origins on the surface present at the beginning of the test.

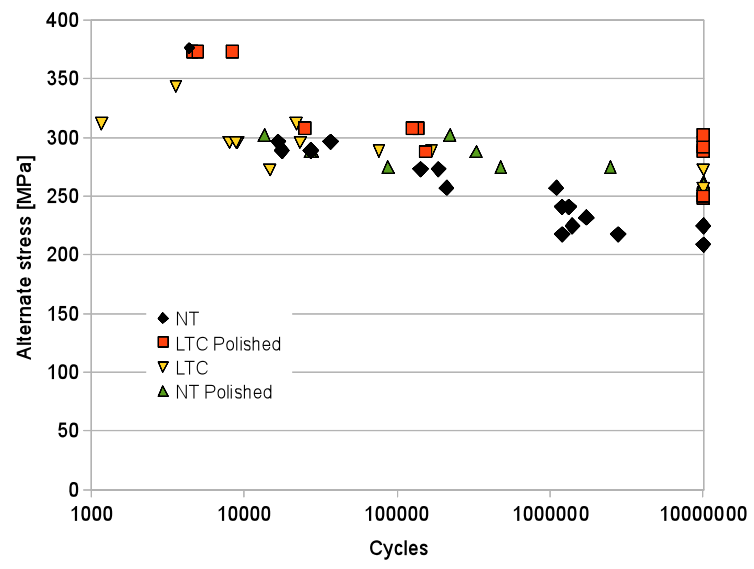

Fig. 3: Effect of the surface roughness on the fatigue life

On the other hand the LTC treatment is much beneficial in the case of the polished specimens, leading to a further increment of the fatigue limit (increasing from nearly $220 \mathrm{MPa}$ for the not treated specimens with $\mathrm{R}=0.8 \mu \mathrm{m}$ rugosity, to $260 \mathrm{MPa}$ for the polished untreated specimens up to nearly $290 \mathrm{MPa}$ for the specimen polished and then LTC with increments of $18 \%$ and $30 \%$ respectively).

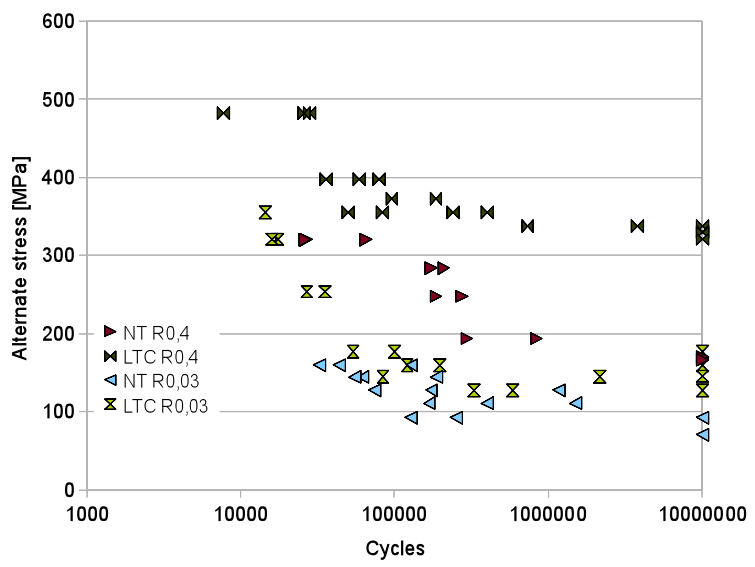

Fig. 4: Effect of different notches on the fatigue life 
The notch effect on the fatigue life for treated and not treated specimens can be evaluated from figure 4. In general it can be seen that the fatigue performances improve both in the case of very sharp notch and the case of a higher notch radius. It must be noticed that in the graph the nominal stress values are reported. They were obtained by dividing the bending moment by the resistance modulus of the neat section, without considering the stress concentration factors.

For the sharp notch a $50 \%$ increment on the fatigue limit is found, even if the nominal stress is very low. At the notch tip the presence of a more or less extended plastic zone is to be expected because the theoretical values of elastic stress would exceed $650 \mathrm{MPa}$, much higher value than the yielding stress.

A higher improvement of the fatigue limit was found in the case of the blunt notch, with a lower stress concentration factor. In fact, the fatigue limit is nearly doubled and it reaches $320 \mathrm{MPa}$ corresponding to a maximum theoretical elastic stress of more than $1100 \mathrm{MPa}$. From this it can be concluded that there was plastic flow just beneath the treated layer.

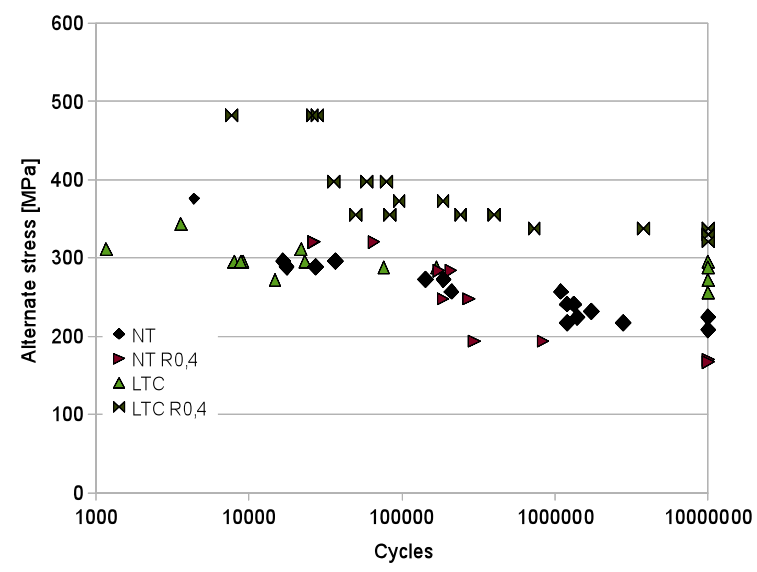

Fig. 5: Apparent notch sensitivity

In figure 5 the behaviour of the smooth specimens is compared with the one of the specimens with a blunt notch.

A limited notch sensitivity is shown for the not treated specimens, that is typical of austenitic stainless steels, while for the treated material a surprising phenomenon is highlighted: the nominal fatigue limit of the notched specimens is significantly higher than the smooth specimens one.

An explanation of this fact can be found only through the mechanism of thermal degradation of the LTC layer.

In [1] an important temperature rise was found during fatigue tests. In this test campaign an infrared thermometer has been used to attempt the temperature measurement, but its spatial resolution was not enough accurate to catch the temperature variation in the notches.

The measured temperature rise as a function of the applied alternate stress is shown in figure 6 .

The better fatigue behaviour of the notched specimens, with a very high nominal maximum stress and a high residual stress field, is due to the smaller fraction of the material that undergoes to this stress value respect to the smooth specimens. In this way the total dissipated energy in form of heat is very few and the good thermal conductivity of steel prevent the temperature from rising significantly.

The smooth specimens behave in a totally different way since the volume of material subject o the maximum stress is much higher (and extended over all the calibrated length) and this leads to higher values of dissipated energy even if the density of the dissipated energy is lower than in the previous 


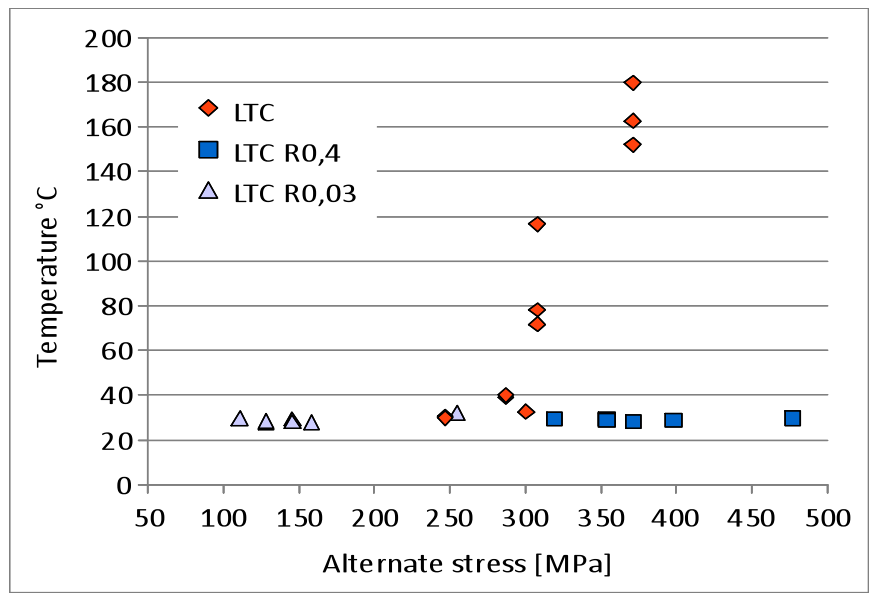

Fig. 6: Temperature rise

case. In this case the temperature increment is high enough to provoke the thermal instability of the carburized layer [9] as verified in [1].

In the following SEM images the fracture surfaces of notched specimens are shown while analogous pictures smooth specimens fracture surfaces, very similar indeed to the ones reported here can be found in [1].

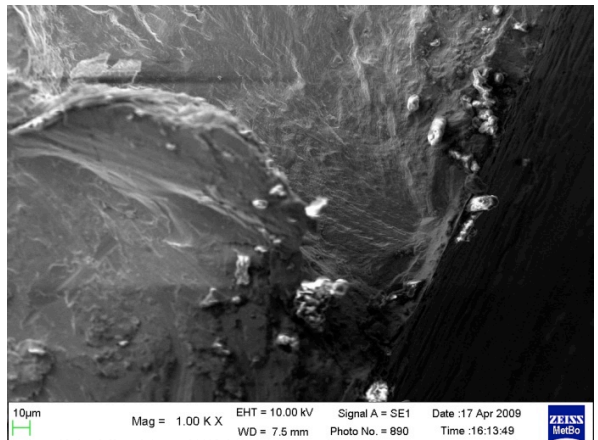

Fig. 7a: Fatigue crack origin in specimens with a blunt notch

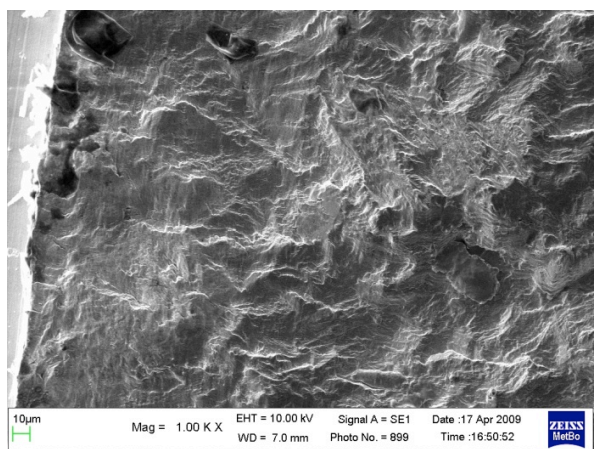

Fig. 8a: Fatigue crack origin in specimens with a sharp notch

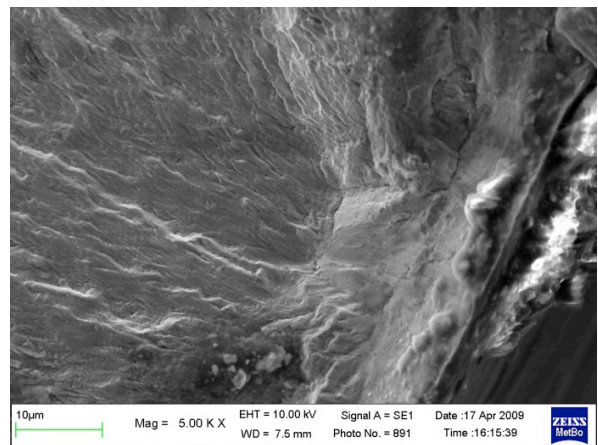

Fig. 7b: Close-up of the fatigue crack origin in specimens with a blunt notch

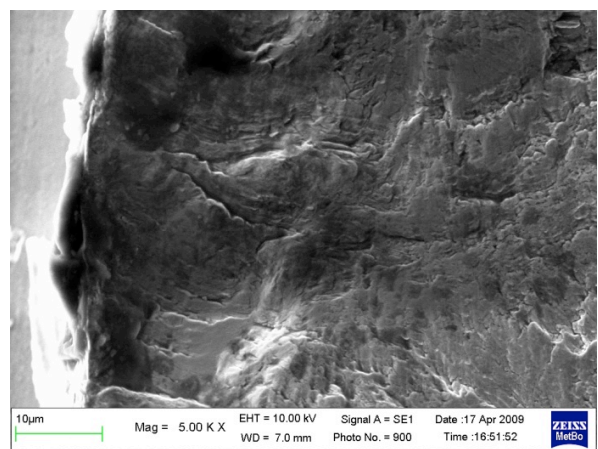

Fig. 8b: Close-up of the fatigue crack origin in specimens with a sharp notch 
The first important observation is that the fracture origin is always sub-surface, in disagreement with what is reported in literature [5]. Second, the LTC layer appears to have lower thickness than the nominal one (around $15 \mu \mathrm{m}$ instead of $33 \mu \mathrm{m}$ ). This fact could be attributed to reduced carbon diffusion during the LCT process near the notches.

\section{Conclusions}

In this paper the results of rotating bending fatigue test on an austenitic stainless steel specimens with different surface roughness, notches and surface LTC treatment were presented and the following conclusions can be drawn:

1) LTC improved the fatigue performances of the AISI316 stainless steel for all the values of stress concentration considered;

2) This improvement is due to the compressive residual stress field that moves the origin of the crack towards the specimen axis and prevent the crack from propagating in the surface layer;

3) In the V-notched specimens the thickness of the LTC layer is lower than the nominal one.

4) The fatigue tests, done at a frequency of $50 \mathrm{~Hz}$ lead to a temperature rise of the smooth specimens, leading to a significant reduction of their fatigue life. Due to this fact the notched specimens had apparently better results.

\section{Acknowledgments}

The author thanks Dr. Vittorio Bordiga from Bodycote for supplying the material and Dr. Iuri Boromei, Dr. Alessandro Morri and Dr. Fabrizio Tarterini of the SMETEC Department for their precious help in the experimental activity

\section{References}

1. L. Ceschini, G. Minak , Surf Coat Technol, 202 , 1778-1784 (2008)

2. G. Minak, Proceedings of the 8th International Conference on Residual Stresses ICRS8, Denver, USA (2008)

3. G. Minak, R. Panciroli, A. Zucchelli, Proceeding of the 20th International Congress of Mechanical Engineering COBEM 2009, Gramado RS, Brasil (2009)

4. K. Tokaji, K. Kohyama, M. Akita, Int J Fatigue, 26 543-551 (2004)

5. M. Akita, K. Tokaji, Surf Coat Technol, 200 6073-6078 (2006)

6. ISO 1143:1975 Metals - Rotating bar bending fatigue testing

7. ISO 12107:2003 Metallic materials - Fatigue testing - Statistical planning and analysis of data

8. T Christiansen and M.A.J Somers, Structure, e9, 1-17 (2006) 